\title{
HOMOSPERMIDINE SYNTHASE OF RHODOPSEUDOMONAS VIRIDIS: SUBSTRATE SPECIFICITY AND EFFECTS OF THE HETEROLOGOUSLY EXPRESSED ENZYME ON POLYAMINE METABOLISM OF ESCHERICHIA COLI
}

\author{
DIETRICH OBER, DOROTHEA THOLL, WILLIAM MARTIN,' \\ AND THOMAS HARTMANN* \\ Institut für Pharmazeutische Biologie, and ${ }^{1}$ Institut für Genetik, \\ Technischen Universität Braunschweig, D-38106 Braunschweig, Germany
}

(Received August 14, 1996; Accepted September 17, 1996)

Homospermidine synthase (HSS) catalyses the formation of the polyamine homospermidine from $2 \mathrm{~mol}$ of putrescine. The general and kinetic properties of purified HSS from Rhodopseudomonas viridis are given and compared with those of the respective enzymes from other sources. The $R$. viridis enzyme is shown to catalyse a number of side reactions: (I) In the presence of putrescine or spermidine as donors of the 4-aminobutyl moiety, various homologous diamines are transformed into the respective $\mathrm{N}$-(4-aminobutyl)derivatives. (II) In the absence of putrescine, spermidine as a substrate yields homospermidine, putrescine and diaminopropane as reaction products. The mechanism of the reactions catalysed by HSS and its role in the formation of uncommon bacterial polyamines are discussed. Overexpression of the homospermidine synthase (hss) gene in Escherichia coli revealed the formation of two HSS-products, homospermidine and $\mathrm{N}$-(4-aminobutyl)-cadaverine, which are absent from wild-type $E$. coli. Expression of the hss gene in $E$. coli does not dramatically affect the pool concentrations of the cellular polyamines.

Homospermidine (hspd) is one of the "uncommon polyamines" which occasionally accompany the ubiquitously distributed amines; i.e., putrescine, spermidine and spermine. It has been found in higher organisms (12) as well as in prokaryotes $(3,6)$. In certain bacterial taxa, hspd even replaces spermidine as the major polyamine and is a useful chemosystematic marker. In higher plants, hspd is the specific precursor of the pathway leading to pyrrolizidine alkaloids, a class of

* Address reprint requests to: Dr. Thomas Hartmann, Institut für Pharmazeutische Biologie, Technischen Universität Braunschweig, Mendelssohnstrasse 1, D-38106 Braunschweig, Germany. 
secondary compounds with functions in the plant's defense against herbivory (7). Hspd is synthesised from 2 mol of putrescine by an unique reaction catalysed by homospermidine synthase (HSS). The enzyme has been purified and characterised from bacteria $(15,17)$ and higher plants $(1,2,13)$. The enzymes from the two different sources are similar in their kinetic and immunological properties. The gene of Rhodopseudomonas viridis HSS has recently been cloned and sequenced (16).

Here, we present some properties of the purified HSS from $R$. viridis, particularly its substrate specificity. Until recently, HSS was assumed to catalyse a specific reaction. We show that this assumption needs to be revised, and that HSS may well be responsible for the formation of hspd analogues such as 4-aminobutylcadaverine (5). Furthermore, we describe the effects of expression of the homospermidine synthase (hss) gene in Escherichia coli, a bacterium in which hspd does not naturally occur, on polyamine metabolism.

\section{MATERIALS AND METHODS}

Rhodopseudomonas viridis (DSM 134) was obtained from the German Collection of Microorganisms and Cell Cultures (DSM Braunschweig, Germany). The strain was cultured anaerobically using the medium according to Ref. (9) as described previously (16). HSS was purified to electrophoretic homogeneity using a three-step purification protocol (16). Enzyme assays were performed in a total volume of $125 \mu 150 \mathrm{~mm}$ potassium phosphate buffer ( $\mathrm{pH} 8.5$ ) containing $1.0 \mathrm{~mm}$ $\left[1,4-{ }^{14} \mathrm{C}\right]$-putrescine $(0.05 \mu \mathrm{Ci} /$ assay $), 0.2 \mathrm{mM} \mathrm{NAD}^{+}$and further additives as indicated. Assays were incubated for 10 to $60 \mathrm{~min}$ at $37^{\circ} \mathrm{C}$. The formation of labelled hspd was followed quantitatively by TLC equipped with a radio-scanner or HPLC coupled to a radioactivity monitor as described previously (1).

Polyamines were analysed by HPLC as benzoyl derivatives according to Ref. (10). A RP-18 column (Nucleosil $25 \mathrm{~cm}, 4 \mathrm{~mm}$ i.d.; Macherey \& Nagel, Dürem, Germany) was applied. Elution was performed isocratically using the solvent system $\mathrm{MeCN}-\mathrm{H}_{3} \mathrm{PO}_{4}(1.5 \%)(40: 60)$, with parallel detection of (a) UV $230 \mathrm{~nm}$ and (b) radioactivity ( 1 ). The retention times $(R t$; $\mathrm{min})$ of the analysed polyamines were as follows: 1,3-diaminopropane, 5.2; putrescine, 5.5; cadaverine, 6.4; 1,6-diaminohexane, 8.7; spermidine, 8.4; sym-homospermidine, 9.5; $\mathrm{N}$-[4-aminobutyl]-1,5-diaminopentane, 11.5; $\mathrm{N}$-[4-aminobutyl]-1,6-diaminohexane, 16.3.

Transformation and expression of the $h s s$ gene with the $T_{7}$ polymerase system in $E$. coli BL21 (14) has been described (16). E. coli BL21 (wild type) and its transformant, BL21/pHsRvT 2.2 , were grown over night at $37^{\circ} \mathrm{C}$ in $200 \mathrm{ml}$ of LB-medium containing $100 \mu \mathrm{g}$ ampilicillin in the case of the transformed strain. Fifty milliliters of fresh LB-medium was added, and cells were induced with $0.4 \mathrm{mM}$ isopropyl- $\beta$-D-thiogalactoside (IPTG) after $1 \mathrm{~h}$. After IPTG induction, $8 \mathrm{ml}$ aliquots of the culture were harvested at intervals as indicated, mixed with $5 \%$ perchloric acid $(\mathrm{v} / \mathrm{v})$ and extracted for $10 \mathrm{~min}$ by sonication. After centrifugation, 
the supernatant was applied to polyamine analysis according to Ref. (10) as given above.

The polyamines were identified as N-carbomethoxy derivatives (NCM derivatives) by GC-MS $(8)$. An aliquot $(1.0 \mathrm{ml})$ of the aqueous enzymatic assay medium was mixed with $20 \mu 1$ of methyl chloroformate and incubated at room temperature for $15 \mathrm{~min}$. The amine NCM derivatives were extracted into diethyl ether (three times, $1 \mathrm{ml}$ each). The extracts were combined and the solvent evaporated. The residue was dissolved in 10-25 $\mu \mathrm{l}$ dichloromethane prior to GC-MS analysis. GC-MS was conducted using a Carlo Erba 5160 gas chromatographer equipped with a $30 \mathrm{~m} \times 0.32 \mathrm{~mm}$ fused-silica column (DB-1) under the following conditions: injector, $250^{\circ} \mathrm{C}$; split-ratio, $1: 20$; injection volume, $1-2 \mu 1$; carrier gas, He 0.75 bar; detector, FID. The capillary column was directly coupled to a Finnigan MAT 4515 quadrupole mass spectrometer. EI-mass spectra were recorded at $40 \mathrm{eV}$. The NCM derivatives of the following diamines (applied as substrates) and polyamines (formed as products) were identified (see Table 1) by their Kovats indices (RI)

Table 1. Substrate specificity of purified HSS from Rhodopseudomonas viridis.

\begin{tabular}{|c|c|c|c|}
\hline & $\begin{array}{l}\text { Substrate(s) } \\
(1 \mathrm{~mm} \text { each })\end{array}$ & $\begin{array}{l}\text { Product(s) formed or expected } \\
\text { to be formed }\end{array}$ & $\begin{array}{c}\text { Relative activity } \\
(\%)\end{array}$ \\
\hline C. & Putrescine & Homospermidine & 100 \\
\hline \multirow[t]{2}{*}{ I. } & 1,3-Diaminopropane & N-(3-Aminopropyl)-1,3-diaminopropane & nd \\
\hline & Cadaverine & $\mathrm{N}$-(5-Aminopentyl)-1,5-diaminopentane & nd \\
\hline \multirow[t]{3}{*}{ II. } & Spermidine & Homospermidine & 10 \\
\hline & & Putrescine & 4 \\
\hline & & 1,3-Diaminopropane & ++ \\
\hline \multirow[t]{11}{*}{ III. } & Putrescine & & \\
\hline & + 1,3-Diaminopropane & Homospermidine & 5 \\
\hline & & Spermidine & 2 \\
\hline & + Cadaverine & Homospermidine & 56 \\
\hline & & $\mathrm{N}$-(4-Aminobutyl)-1,5-diaminopentane & 6 \\
\hline & + 1,6-Diaminohexane & Homospermidine & 54 \\
\hline & & N-(4-Aminobutyl)-1,6-diaminohexane & 5 \\
\hline & + 1,7-Diaminoheptane & Homospermidine & 63 \\
\hline & & N-(4-Aminobutyl)-1,7-diaminoheptane & $\operatorname{tr}$ \\
\hline & + Spermidine & Homospermidine & 73 \\
\hline & & 1,3-Diaminopropane & ++ \\
\hline \multirow[t]{7}{*}{ IV. } & Spermidine & & \\
\hline & + Cadaverine & Homospermidine & 5 \\
\hline & & N-(4-Aminobutyl)-1,5-diaminopentane & 6 \\
\hline & & 1,3-Diaminopropane & ++ \\
\hline & + 1,6-Diaminohexane & Homospermidine & 6 \\
\hline & & N-(4-Aminobutyl)-1,6-diaminohexane & $<1$ \\
\hline & & 1,3-Diaminopropane & ++ \\
\hline
\end{tabular}

Activity with putrescine as substrate was set as $100 \%$ (i.e., 9 pkat per assay). The products were identified by GC-MS and assayed quantitatively by radio HPLC. Putrescine, spermidine and cadaverine were applied as ${ }^{14} \mathrm{C}$-labelled substrates. nd, not detectable; tr, trace amounts; ++ , unequivocally identified by GC-MS; quantification impossible due to lack of labelling. 
and molecular mass ion $\left(\mathrm{M}^{+}\right)$: 1,3-diaminopropane, RI 1485, [ $\left.\mathrm{M}^{+}\right] \mathrm{m} / z \quad 190$;

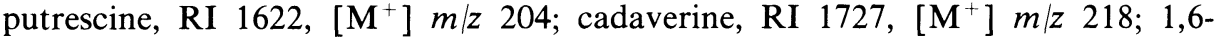

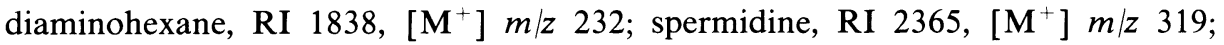
sym-homospermidine, RI 2467, [ $\left.\mathrm{M}^{+}\right] \mathrm{m} / \mathrm{z}$ 333; N-[4-aminobutyl]-1,5-diaminopentane, RI 2570, [ $\left.\mathrm{M}^{+}\right] m / z$ 347; N-[4-aminobutyl]-1,6-diaminohexane, RI 2678, $\left[\mathbf{M}^{+}\right] m / z 361$.

The following radioactively labelled tracers were applied: $\left[1,4-{ }^{14} \mathrm{C}\right]$ putrescine $\left(108 \mathrm{mCi} \cdot \mathrm{mmol}^{-1}\right), \quad\left[{ }^{14} \mathrm{C}\right]$ spermidine $\left(\mathrm{N}\right.$-(3-aminopropyl)- $\left[1,4-{ }^{14} \mathrm{C}\right]$ tetramethylene-1,4-diamine $)\left(109 \mathrm{mCi} \cdot \mathrm{mmol}^{-1}\right)$ and $\mathrm{L}$ - $\left[\mathrm{U}_{-}{ }^{14} \mathrm{C}\right]$ lysine $\left(312 \mathrm{mCi} \cdot \mathrm{mmol}^{-1}\right)$, which were purchased from Amersham (Braunschweig, Germany). [U- $\left.{ }^{14} \mathrm{C}\right]-$ Cadaverine was prepared from labelled lysine with L-lysine decarboxylase (Sigma, Heidelberg, Germany).

\section{RESULTS}

\section{General and kinetic properties of HSS}

$\mathrm{pH}$ and temperature. HSS activity shows a pH optimum at $8.8-9.0$ in $50 \mathrm{~mm}$ potassium phosphate or bistris-propane buffers. Subsequently, all enzyme assays were carried out in $50 \mathrm{~mm}$ potassium phosphate buffer $\mathrm{pH}$ 8.5. Enzyme activity increases with temperature up to $c a 45^{\circ} \mathrm{C}$ and decreases sharply at higher temperatures. The activation energy $\left(E_{\mathrm{a}}\right)$ of the HSS catalysed reaction determined graphically according to the Arrhenius equation (11) was found to be $55.4 \mathrm{~kJ}$. $\mathrm{mol}^{-1}$. R. viridis $\mathrm{HSS}$ is activated by $\mathrm{K}^{+}$ions. In the absence of $\mathrm{K}^{+}$, HSS activity is less than $50 \%$ of the optimal activity measured at $\mathrm{K}^{+}$concentrations of $50 \mathrm{~mm}$. At $\mathrm{K}^{+}$concentrations $>75 \mathrm{~mm}$, HSS activity decreases again continuously $(50 \%$ inhibition at $c a 200 \mathrm{mM} \mathrm{K}^{+}$). A comparable but strict requirement for $\mathrm{K}^{+}$ions has been demonstrated for HSS from Acinetobacter tartarogenes (17). Subsequently, all HSS assays were carried out in standard buffer containing $50 \mathrm{~mm} \mathrm{~K} \mathrm{~K}^{+}$.

Substrate specificity. A number of putrescine analogues as well as spermidine were tested for the ability to substitute for putrescine as the only substrate or in the ability to replace, as a substrate, one of the $2 \mathrm{~mol}$ of putrescine. The results obtained with purified HSS are summarized in Table 1. With various substrates and substrate combinations (Table 1, I-IV), a number of unexpected reactions catalysed by HSS were observed. The results can be summarized as follows: (I) Putrescine can not be substituted as the sole substrate by homologous diamines; e.g., 1,3-diaminopropane or 1,5-diaminopentane (cadaverine). (II) In the absence of putrescine, spermidine as the sole substrate yields hspd (about 10\% of control), putrescine and diaminopropane as enzymatic products. (III) In the presence of putrescine, various diamines of the homologous series 1,3-diaminopropane to 1,7diaminoheptane are incorporated into the respective $\mathrm{N}$-(4-aminobutyl)-derivatives, which are formed as minor products (amounts between traces and 6\% of control) in addition to hspd. (IV) $\mathrm{N}$-(4-Aminobutyl)-derivatives are also formed if putrescine is substituted by spermidine. 
The products formed by the HSS-catalysed reaction were unequivocally identified by GC-MS. When ${ }^{14} \mathrm{C}$-labelled spermidine was applied as the only substrate, four labelled products were formed: the three polyamines given in Table 1, II and a compound tentatively identified as $\Delta^{1}$-pyrroline. It shows the same chromatographic behaviour as authentic $\Delta^{1}$-pyrroline, the spontaneous cyclisation product of 4-aminobutanal. This is the only direct evidence to date for the role of 4aminobutanal as an intermediate in HSS-catalysed reactions.

\section{Effect of HSS expression on polyamine metabolism in E. coli}

$E$. coli strain BL21 did not possess HSS activity, whereas its transformant strain, BL21/pHsRvT 2.2 , which contains the hss gene, expressed high levels of HSS activity in crude lysates; i.e., $5.7 \mathrm{nkat} / \mathrm{ml}$ prior to the induction of $\mathrm{T}_{7}$-RNA polymerase with IPTG and up to $11.5 \mathrm{nkat} / \mathrm{ml}$ after induction (16). The two strains were grown under identical conditions and analysed for their polyamine patterns and contents. Samples were taken prior to induction $\left(T_{0}\right)$ and $1-2 \mathrm{~h}$ after the addition of IPTG (Fig. 1). The wild-type BL21 strain contained cadaverine, putrescine and spermidine (Fig. 1A). In addition to these, the amine pattern of the

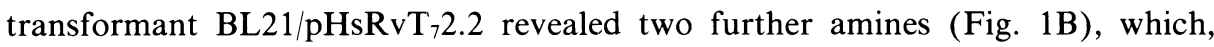
during HPLC analysis, displayed the same elution profiles as hspd and $\mathrm{N}$-(4aminobutyl)-cadaverine. The identities of the two amines were unequivocally confirmed by GC-MS analysis of the respective NCM derivatives. Both amines were absolutely undetectable in wild-type $E$. coli. The pool concentrations of the amines were not very different in the two strains. Although the pool concentrations of putrescine and spermidine were about two- to threefold lower in the transformant strain, the sum of the putrescine equivalents were almost the same in the two strains (Fig. 1). The addition of IPTG did not significantly influence the amine
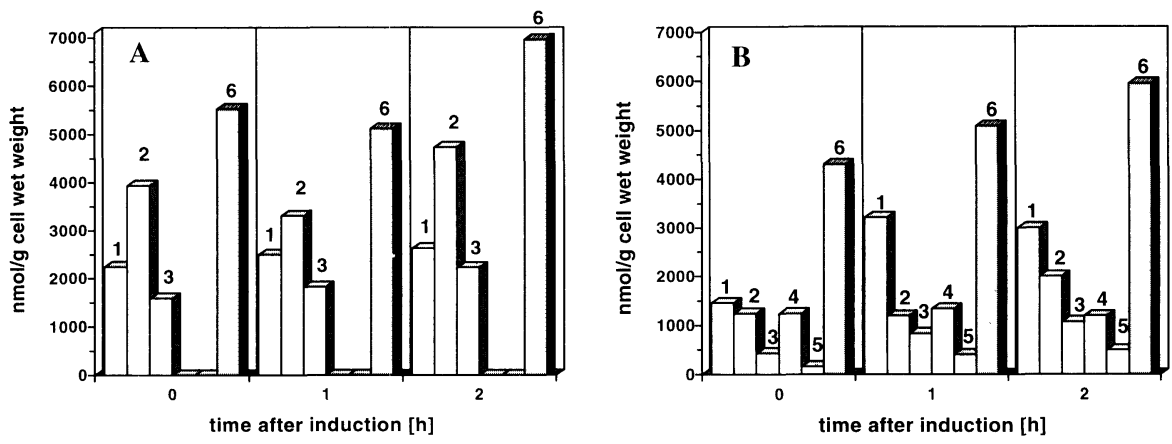

Fig. 1. Polyamine pools of (A) Escherichia coli strain BL21 (wild type) and (B) strain $\mathrm{BL} 21 / \mathrm{pHsRvT}_{7} 2.2$ containing the Rhodopseudomonas viridis hss gene.

Samples were analysed 0,1 , and $2 \mathrm{~h}$ following induction with IPTG. 1, cadaverine; 2, putrescine; 3, spermidine; 4, homospermidine; 5, N-(4-aminobutyl)-cadaverine; 6 , total put-equivalents (i.e., sum $(\mathrm{nmol})$ of putrescine + spermidine $+2 \cdot(\mathrm{hspd})+4$ aminobutylcadaverine). 
levels in either the transformant or the wild-type strain. Despite the high expression of HSS protein (i.e., approximately $40-50 \%$ of the soluble protein in crude extracts) in the transformed $E$. coli strain (16), there seemed to be no drastic effect on the polyamine metabolism. The common polyamine precursor putrescine was neither heavily directed into hspd, as one would expect from the high overexpression of HSS, nor did the additional drain of putrescine into the HSS products have a significant effect on the rate of its formation.

\section{DISCUSSION}

HSS was purified from the two bacterial species $R$. viridis and $A$. tartarogenes as well as from higher plants which produce pyrrolizidine alkaloids; e.g., Eupatorium cannabinum. The properties of the three enzymes are compared in Table 2. There are considerable similarities between the different enzymes including their molecular organisation, $\mathrm{pH}$ dependency, activation energy, coenzyme requirements and competitive inhibitors.

Until recently, putrescine was assumed to be the specific substrate of HSS (1,

Table 2. Comparison of the properties of HSS from Rodopseudomonas viridis, Acinetobacter tartarogenes and the plant Eupatorium cannabinum.

\begin{tabular}{|c|c|c|c|}
\hline Property & R. viridis $^{a}$ & A. tartarogenes ${ }^{b}$ & E. cannabinum ${ }^{c}$ \\
\hline Genuine $M r(\mathrm{kD})$ & 102 & 102 & 72 \\
\hline Subunit $M r(\mathrm{kD})$ & $52.6^{d}$ & 52 & - \\
\hline $\mathrm{p} I(\mathrm{pH})$ & 3.9 & 5.0 & - \\
\hline$E_{\mathrm{a}}\left(\mathrm{kJ} \cdot \mathrm{mol}^{-1}\right)$ & 55.4 & - & 54 \\
\hline pH-optimum & $8.8-9.0$ & 8.7 & 9.0 \\
\hline Optimal $\mathrm{K}^{+}(\mathrm{mM})$ & 50 & 50 & No effect \\
\hline$K_{\mathrm{m}}[$ put] $(\mu \mathrm{M})$ & 270 & 280 & 13.5 \\
\hline \multicolumn{4}{|l|}{ In presence of put ${ }^{e}$} \\
\hline$K_{\mathrm{m}}[\mathrm{spd}](\mu \mathrm{M})$ & 1,500 & - & 12 \\
\hline$V_{\max } / K_{\mathrm{m}}$ & 1.1 & - & 733 \\
\hline \multicolumn{4}{|l|}{ In presence of $\mathrm{spd}^{e}$} \\
\hline$K_{\mathrm{m}}[\mathrm{put}](\mu \mathrm{M})$ & 1,700 & - & 15 \\
\hline$V_{\max } / K_{\mathrm{m}}$ & 10.0 & - & 733 \\
\hline$K_{\mathrm{m}} \mathrm{NAD}^{+}(\mu \mathrm{M})$ & 1.0 & 1.0 & 3.0 \\
\hline $\mathrm{NADP}^{+}$as coenzyme ${ }^{f}$ & 68 & 0 & $<2$ \\
\hline \multicolumn{4}{|l|}{ Competitive inhibitors } \\
\hline$K_{\mathrm{i}}$ diaminopropane $(\mu \mathrm{M})$ & 5 & 13 & 6.3 \\
\hline$K_{\mathrm{i}} \operatorname{hspd}(\mu \mathrm{M})$ & 5.5 & - & 0.95 \\
\hline$K_{\mathrm{i}} \mathrm{NADH}(\mu \mathrm{M})$ & 1.8 & 6 & +8 \\
\hline
\end{tabular}

a Data according to Refs. $(2,15,16)$ and this paper.

$b$ Ref. (17).

c Refs. $(1,2)$.

d Calculated from the deduced amino acid sequence of the sequenced gene.

$e$ Concentrations of put and spd, respectively, $1 \mathrm{mM}$ (R. viridis) and $0.1 \mathrm{mM}$ (E. canabinum).

$f$ Activity with $\mathrm{NAD}^{+}=100 \%$.

s Significant inhibition at levels $>2 \mu \mathrm{M}$; no clear competitive kinetics. 
15,17). However, it has been found that plant HSS is capable of transferring the 4-aminobutyl moiety of spermidine to putrescine yielding hspd and diaminopropane in the presence of $\mathrm{NAD}^{+}(2)$. In this reaction, in which one $\mathrm{C}_{4}$-unit of hspd is formed from spermidine and the other from putrescine, spermidine is used as a substrate with exactly the same kinetic affinity $\left(K_{\mathrm{m}}\right)$ and efficiency $\left(V_{\max } / K_{\mathrm{m}}\right)$ as putrescine (Table 2). HSS from $R$. viridis shows the same behaviour (Table 2). Differences, however, exist in the respective $V_{\max } / K_{\mathrm{m}}$ ratios, indicating that the bacterial enzyme uses spermidine as a donor of the 4-aminobutyl moiety with the same affinity but a 10 -fold lower efficiency than putrescine (2). To account for the role of spermidine as a substitute for one of the two putrescine moieties, the formation of hspd catalysed by HSS must be modified as illustrated in Fig. 2.

In addition to the major substrates putrescine and spermidine, bacterial HSS catalyses a number of minor reactions (Table 1). The most remarkable side reaction is the transformation of spermidine, when given as a sole substrate, into hspd, putrescine and diaminopropane (Table 1). A possible mechanism to account for the products formed is outlined in Fig. 3. The formation of putrescine and diaminopropane as products predicts the imines I and II as intermediates, from which the two diamines may be released. The remaining aminoaldehydes may be combined with putrescine (yielding spermidine or hspd, respectively) or diaminopropane (yielding spermidine). Since 10\% hspd (in comparison to the relative activity of the control, Table 1) is formed, a considerable amount of free putrescine must be formed. The percentage of analogously formed spermidine was not calculated because it can not be discriminated from substrate spermidine.

Another type of side reaction is the combination of putrescine with homologous diamines, leading to the respective homospermidine homologues (Table 1). These reactions can easily be described by the scheme in Fig. 3. The only assumption required is that the putrescine-derived 4-aminobutyl moiety is combined with the respective diamine; e.g., with diaminopropane yielding spermidine. The formation of 4-butylcadaverine from putrescine + cadaverine as a by-product

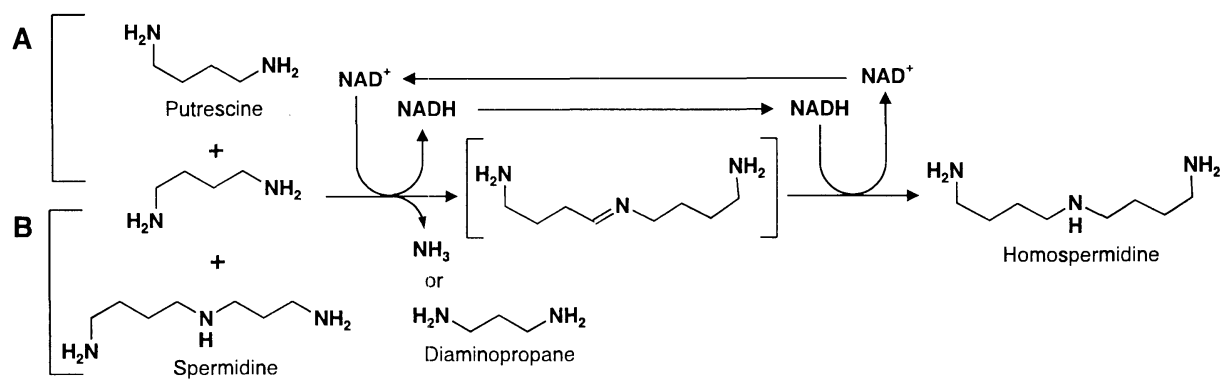

Fig. 2. Basic reactions catalysed by homospermidine synthase.

(A) Formation of homospermidine + ammonia from $2 \mathrm{~mol}$ of putrescine. (B) Formation of homospermidine +diaminopropane from $1 \mathrm{~mol}$ putrescine and $1 \mathrm{~mol}$ spermidine. $\mathrm{NAD}^{+}$functions as a coenzyme, catalysing the hydrogen (hydride) transfer intramolecularly in a stoichiometric manner (2). 


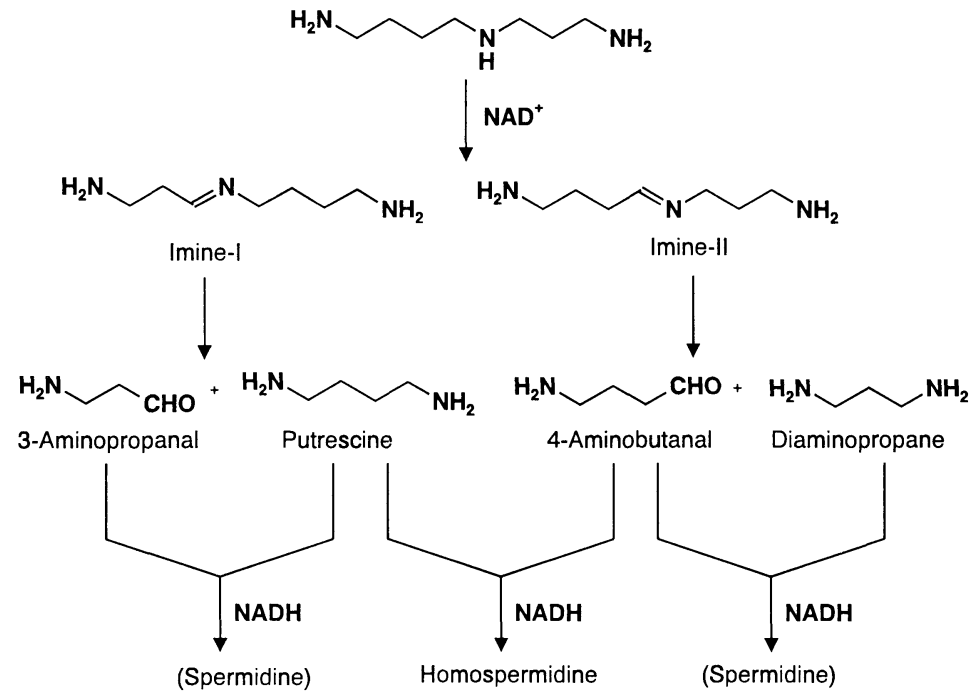

Fig. 3. Suggested mechanism by which homospermidine synthase catalyses the transformation of spermidine to putrescine, diaminopropane and homospermidine.

The spermidine eventually formed in the process can not be discriminated from the spermidine given as a substrate.

of purified HSS from $A$. tartarogenes was also demonstrated (17). No products, however, were formed when putrescine homologues (e.g., diaminopropane or cadaverine) were offered as substrates in absence of putrescine (Table 1).

The formation of 4-aminobutylcadaverine by the $E$. coli transformant containing the hss gene directly demonstrates that, under in vivo conditions, HSS may catalyse the formation of hspd homologues if the respective substrates (e.g., cadaverine) are present. Recently, a number of unknown polyamines were found in the nodules of various plant-microbe symbiotic associations (4). The unknown amine in the root nodules of adzuki beans (Vigna angularis, Fabaceae) was identified as 4-aminobutylcadaverine. It was isolated together with hspd from the nodule bacteroids (Bradyrhizobium japonicum) (5). Using the crude cell extracts of bacteroids and ${ }^{15} \mathrm{~N}$-labelled putrescine, the authors showed that the aminobutyl moiety is transferred to one of the amino groups of cadaverine. This coincides with our results. Furthermore, we suggest that side reactions such as those described here are not unique to $R$. viridis HSS, but may also be found with the enzymes from other bacterial sources. Further studies are needed to clarify the importance of HSS side reactions in the formation of homospermidine analogues and other uncommon polyamines in bacteria.

The authors thank Dr. L. Witte for GC-MS analysis. This study was supported by grants of the Deutsche Forschungsgemeinschaft (DFG) and Fonds der Chemischen Industrie to T. H. 


\section{REFERENCES}

1) Böttcher, F., Adolf, R.-D., and Hartmann, T., Homospermidine synthase, the first pathwayspecific enzyme in pyrrolizidine alkaloid biosynthesis. Phytochemistry, 32, 679-689 (1993).

2) Böttcher, F., Ober, D., and Hartmann, T., Biosynthesis of pyrrolizidine alkaloids: Putrescine and spermidine are essential substrates of enzymatic homospermidine formation. Can. J. Chem., 72, 80-85 (1994).

3) Busse, J. and Auling, G., Polyamine pattern as a chemotaxonomic marker within the Proteobacteria. Syst. Appl. Microbiol., 11, 1-8 (1988).

4) Fujihara, S., Abe, H., Minakawa, Y., Akao, S., and Yoneyama, T., Polyamines in nodules from various plant-microbe symbiotic associations. Plant Cell. Physiol., 35, 1127-1134 (1994).

5) Fujihara, S., Abe, H., and Yoneyama, T., A new polyamine 4-aminobutylcadaverine. J. Biol. Chem., 270, 9932-9938 (1995).

6) Hamana, K. and Matsuzaki, S., Polyamines as a chemotaxonomic marker in bacterial systematics. Crit. Rev. Microbiol., 18, 261-283 (1992).

7) Hartmann, T. and Witte, L., Chemistry, biology and chemoecology of the pyrrolizidine alkaloids. In Alkaloids: Chemical and Biological Perspectives, Vol. 9, ed. by Pelletier, S. W., Elsevier Sci. Publ., Oxford (1995), p. 155-233.

8) Husek, P., Huang, Z. H., and Sweely, C. C., Gas chromatographic determination of amines, aminoalcohols and acids after treatment with alkyl chloroformates. Anal. Chim. Acta, 259, 185192 (1992).

9) Malik, K. A., A modified method for the cultivation of phototrophic bacteria. J. Microbiol. Methods, 1, 343-352 (1983).

10) Redmond, J. W. and Tseng, A., High-pressure liquid chromatography determination of putrescine, cadaverine, spermidine and spermine. J. Chromatogr., 170, 479-481 (1979).

11) Segel, I. H., Enzyme Kinetics, John Wiley \& Sons, New York (1975).

12) Smith, T. A., Polyamines. Ann. Rev. Plant Physiol., 36, 117-143 (1985).

13) Srivenugopal, K. S. and Adiga, P. R., Enzymatic synthesis of sym-homospermidine in Lathyrus sativus (grass pea) seedlings. Biochem. J., 190, 461-464 (1980).

14) Studier, F. W., Rosenberg, A. H., Dunn, J. J., and Dubendorff, J. W., Use of $T_{7}$ RNA polymerase to direct expression of cloned genes. Methods Enzymol., 185, 60-89 (1990).

15) Tait, G. H., The formation of homospermidine by an enzyme from Rhodopseudomonas viridis. Biochem. Soc. Trans., 7, 199-200 (1979).

16) Tholl, D., Ober, D., Martin, W., Kellermann, J., and Hartmann, T., Purification, molecular cloning and heterologous expression of homospermidine synthase from Rhodopseudomonas viridis. Eur. J. Biochem., 240, 373-379 (1996).

17) Yamamoto, S., Nagata, S., and Kusaba, K., Purification and characterization of homospermidine synthase in Acinetobacter tartarogenes ATCC 31105. J. Biochem., 114, 45-49 (1993). 